\title{
Polypoidal lesions of the gastrointestinal tract
}

\section{Palzum Sherpa ${ }^{1,2}$, Abhimanyu Jha ${ }^{2,3}$, Sudhamshu Koirala ${ }^{2}$, Rojan Ghimire ${ }^{2}$}

\author{
${ }^{1}$ Department of Pathology, Patan Academy of Health Sciences, Lalitpur, Nepal \\ ${ }^{2}$ Department of Pathology, Om Hospital and Research Centre, Kathmandu, Nepal \\ ${ }^{3}$ Department of Pathology, Tribhuvan University Teaching Hospital, Kathmandu, Nepal
}

\section{Keywords: \\ Gastrointestinal tract; Polypoidal lesion; Neoplastic;}

\begin{abstract}
Background: With increasing usage of endoscopic procedures, gastrointestinal polypoidal lesions are commonly encountered specimens. Histopathological examination is crucial as biological behavior is dependent on its pathological nature.

Materials and Methods: A retrospective descriptive study performed in Pathology department, Om Hospital and Research Centre from January 2017 to June 2019. The study included lesions received as polyp or polypoidal lesions of gastrointestinal tract for histopathological examination. Data was analysed using SPSS version 17.0. Gender, number and site were analysed using Chi square test to evaluate its association with neoplastic nature. Correlation with age and size was tested with Pearson's correlation coefficient.
\end{abstract}

Results: Among 150 cases of gastrointestinal tract polypoidal lesions, 58\% were seen in male and $42 \%$ in female. Hyperplastic polyp and conventional adenoma were the commonest non-neoplastic and neoplastic lesions respectively. The age of patients ranged from 7 to 84 years with a mean age of 50 years. Rectosigmoid region was the commonest site. 134 patients had single and 16 had multiple polypoidal lesions. Most polypoidal lesion had size $<1 \mathrm{~cm}$. Gender, age, number and size showed no correlation with neoplastic nature. A significant association was found with site with notably higher number of neoplastic lesions in large intestine.

Conclusion: A spectrum of histological types of polypoidal lesions were found in gastrointestinal tract, most frequently in colorectal region. Hyperplastic polyp and adenomatous polyp were the commonest non-neoplastic and neoplastic lesions respectively. A notably higher number of polypoidal lesions in the large intestine were found to be neoplastic in nature.

\section{Correspondence:}

Dr. Palzum Sherpa, $M D$

Assistant Professor, Department of Pathology

Patan Academy of Health Sciences, Lalitpur, Nepal

ORCID ID: 0000-0001-7613-8485

Email: palzumsherpa@pahs.edu.np

Reveived : January $17^{\text {th }} 2020$; Accepted : March $3^{\text {rd }} 2020$

Citation: Sherpa P, Jha A, Koirala S, Ghimire R. Polypoidal lesions of the gastrointestinal tract. JPN 2020;10:1625-9 DOI 10.3126/jpn.v10i1.27743

Copyright: This is an open-access article distributed under the terms of the Creative Commons Attribution 4.0 International License, which permits unrestricted use, distribution, and reproduction in any medium, provided the original author and source are credited.

\section{INTRODUCTION}

Gastrointestinal (GI) polypoidal lesions are nodules or mass that project above the level of surrounding mucosa and protrudes into the lumen. They may arise as a result of epithelial or stromal cell hyperplasia, inflammation, ectopia and neoplasia. ${ }^{1}$ They may occur anywhere in the GI tract but are most common in the colorectal region..$^{1-3}$ With increasing usage of endoscopic procedures, GI polypoidal lesions are commonly encountered specimens in histopathology practice. 
Polypoidal lesions with malignant potential are classified as neoplastic whereas non-neoplastic ones have none or lesser possibility of malignant transformation. ${ }^{3}$ The presence or potential risk of malignancy in these polypoidal lesions is the key concern. ${ }^{4}$ The size and site of the polyp and age of the patient are found to be significant risk factors for development of malignancy.5-7 Histopathological examination is crucial as the biological behavior is dependent on its pathological nature.

This study aims to assess the prevalence and histological nature of polypoidal lesions of the GI tract received at histopathology department of Om Hospital and Research Centre, Kathmandu, Nepal. It evaluates the age, gender and anatomical site wise distribution as well as number and size of the polypoidal lesions. Further the association of patient factors (age and gender) and characteristics of polypoidal lesion (number, size and site) with neoplastic nature is analysed. This study could help us gain an insight into the clinico-pathological characteristics of polypoidal lesions of the GI tract in the Nepalese population.

\section{MATERIALS AND METHODS}

This is a retrospective descriptive study conducted in the Department of Pathology at Om Hospital and Research Centre, Kathmandu, Nepal. The study included all lesions identified endoscopically as polyp or polypoidal lesion of the gastrointestinal tract which was biopsied and received at histopathology laboratory for examination. The study sample comprised of 150 polypoidal lesions of the GI tract received over a period of two and half years from January 2017 to June 2019. All the relevant data were retrieved from the archived reports and entered and coded in an excel sheet. The data variables were histopathology number, age, gender, histopathological diagnosis, anatomical site, number and size of the polypoidal lesions. Analysis of the data was performed using SPSS version 17.0. The variables were summarized using mean, percentage and range. The data was represented with tables and bar diagram. Gender, number and site of polypoidal lesions were analysed using

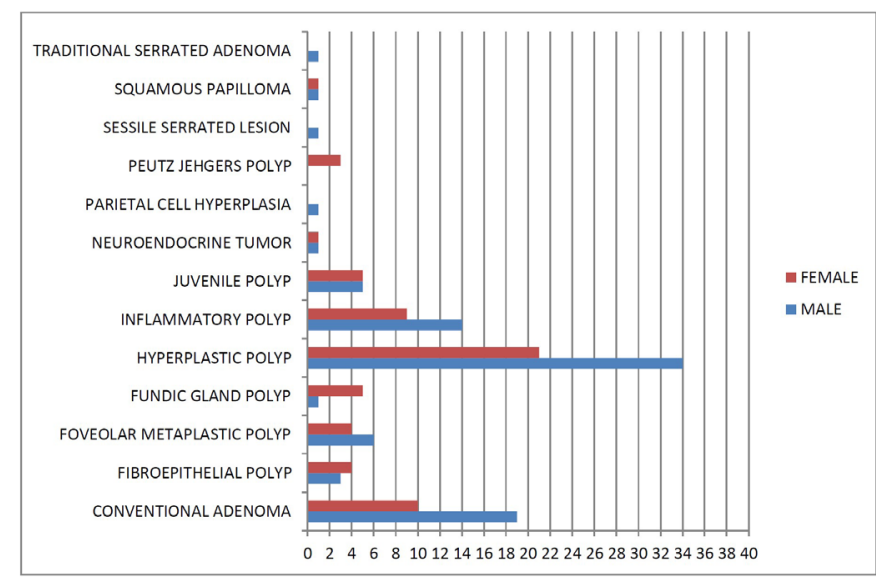

Figure 1: Gender wise distribution of histological types of polypoidal lesions
Chi square test to evaluate its association with neoplastic nature. The correlation with continuous variables (age and size of polypoidal lesion) was tested with the help of Pearson's correlation coefficient. The level of significance was set at 5 percent.

\section{RESULTS}

Of the 150 cases of GI tract polypoidal lesions, 87 (58\%) were seen in male and $63(42 \%)$ in female with a male to female ratio of 1.4:1. Gender wise distribution of the various histological types of polypoidal lesions is illustrated in figure 1. Majority (117 cases, 78\%) of the lesions were nonneoplastic and 33 cases $(22 \%)$ were neoplastic. Hyperplastic polyp (55 cases, 37\%) and conventional adenoma (29 cases, $19 \%$ ) were the commonest non-neoplastic and neoplastic polypoidal lesions respectively (Table 1).

Amongst the conventional adenomas, 25 had tubular and four had tubulovillous morphology. High grade dysplasia was noted in three of these cases. The age of the patients ranged from 7 to 84 years with a mean age of 50 years. The mean age for the neoplastic and non-neoplastic category was 54 and 48 years respectively. Maximum number of cases $31(21 \%)$ was noted in 41-50 years age group followed by $30(20 \%)$ cases in 51-60 years age group (Table 2 ). Rectosigmoid region was the commonest site (56 cases, $37.5 \%$ ) followed by colon (35 cases, $23.5 \%$ ) and stomach (32 cases, 21.5\%). The most frequently found polyp in stomach and rectosigmoid region was hyperplastic polyp, in duodenum foveolar metaplastic polyp and conventional adenoma in colon. There were two cases of neuroendocrine tumor grade 1, one in duodenum and other in recto-sigmoid location (Table 3). 134 patients had single polypoidal lesion and multiple lesions were noted in 16 patients. The size of the polypoidal lesion was $<1 \mathrm{~cm}$ in 136 cases, $1-1.9 \mathrm{~cm}$ and $\geq 2 \mathrm{~cm}$ in 7 cases each.

Analysis of gender, number, size of polypoidal lesions and age of the patient with categories of neoplastic versus non-neoplastic was not statistically significant. However, a significant association $(p=0.008)$ was found with the site of polypoidal lesions, with notably higher number of neoplastic lesions in the large intestine (Table 4 and 5).

\section{DISCUSSION}

A notably higher number of GI polypoidal lesions were found in males compared to females corroborating data from various studies. ${ }^{3,7-9}$ Majority $(n=117,78 \%)$ of the polypoidal lesions in our study were non-neoplastic. This finding is consistent with that of a study performed in Nepal by Gurung et al in which $70 \%$ GI polyps were nonneoplastic. ${ }^{2}$ In contrast, neoplastic polypoidal lesions were more prevalent in studies performed by Manakkad et al in India and Mirzaie et al in Iran. ${ }^{7,9}$ 
Table 1: Histological types of polypoidal lesions

\begin{tabular}{|c|c|c|c|}
\hline \multicolumn{2}{|c|}{ Type of Polyp } & \multirow{2}{*}{$\begin{array}{c}\text { Number (\%) } \\
29(19)\end{array}$} & \multirow[t]{2}{*}{ Overall } \\
\hline \multirow{4}{*}{ Neoplastic } & Conventional adenoma & & \\
\hline & Sessile serrated lesion & $1(0.5)$ & \multirow{3}{*}{$33(22 \%)$} \\
\hline & Traditional serrated adenoma & $1(0.5)$ & \\
\hline & Well differentiated NET & $2(1.5)$ & \\
\hline \multirow{9}{*}{ Non-neoplastic } & Fibroepithelial polyp & $7(4.5)$ & \multirow{9}{*}{$117(78 \%)$} \\
\hline & Foveolar metaplastic polyp & $10(7)$ & \\
\hline & Fundic gland polyp & $6(4)$ & \\
\hline & Hyperplastic polyp & $55(37)$ & \\
\hline & Inflammatory polyp & $23(15)$ & \\
\hline & Juvenile polyp & $10(7)$ & \\
\hline & Parietal Cell hyperplasia & $1(0.5)$ & \\
\hline & Peutz Jehgers polyp & $3(2)$ & \\
\hline & Squamous papilloma & $2(1.5)$ & \\
\hline
\end{tabular}

Table 2: Age wise distribution of histological types of polypoidal lesions

\begin{tabular}{|c|c|c|c|c|c|c|c|c|c|c|}
\hline \multicolumn{11}{|c|}{ Age group (Year) } \\
\hline & 0-10 & $11-20$ & $21-30$ & $31-40$ & $41-50$ & $51-60$ & $61-70$ & $71-80$ & $81-90$ & Total \\
\hline Conventional adenoma & 0 & 0 & 2 & 3 & 4 & 9 & 5 & 6 & 0 & $29(19 \%)$ \\
\hline Fibroepithelial polyp & 0 & 0 & 0 & 3 & 1 & 0 & 2 & 1 & 0 & $7(4.5 \%)$ \\
\hline $\begin{array}{l}\text { Foveolar metaplastic } \\
\text { polyp }\end{array}$ & 0 & 0 & 1 & 3 & 2 & 1 & 1 & 1 & 1 & $10(7 \%)$ \\
\hline Fundic gland polyp & 0 & 0 & 0 & 0 & 3 & 1 & 2 & 0 & 0 & $6(4 \%)$ \\
\hline Hyperplastic polyp & 0 & 2 & 6 & 10 & 9 & 12 & 11 & 4 & 1 & $55(37 \%)$ \\
\hline Inflammatory polyp & 0 & 0 & 4 & 2 & 6 & 5 & 4 & 2 & 0 & $23(15 \%)$ \\
\hline Juvenile polyp & 1 & 1 & 2 & 3 & 2 & 0 & 1 & 0 & 0 & $10(7 \%)$ \\
\hline Neuroendocrine tumor & 0 & 0 & 0 & 1 & 1 & 0 & 0 & 0 & 0 & $2(1.5 \%)$ \\
\hline Parietal cell hyperplasia & 0 & 0 & 0 & 0 & 0 & 0 & 1 & 0 & 0 & $1(0.5 \%)$ \\
\hline Peutz Jehgers polyp & 0 & 0 & 0 & 1 & 2 & 0 & 0 & 0 & 0 & $3(2 \%)$ \\
\hline Sessile serrated lesion & 0 & 0 & 1 & 0 & 0 & 0 & 0 & 0 & 0 & $1(0.5 \%)$ \\
\hline Squamous papilloma & 0 & 0 & 0 & 0 & 1 & 1 & 0 & 0 & 0 & $2(1.5 \%)$ \\
\hline $\begin{array}{l}\text { Traditional serrated } \\
\text { adenoma }\end{array}$ & 0 & 0 & 0 & 0 & 0 & 1 & 0 & 0 & 0 & $1(0.5 \%)$ \\
\hline Total & $1(0.5 \%)$ & $3(2 \%)$ & $16(11 \%)$ & $26(17 \%)$ & $31(21 \%)$ & $30(20 \%)$ & $27(18 \%)$ & $14(9 \%)$ & $2(1.5 \%)$ & $150(100 \%)$ \\
\hline
\end{tabular}

In the present study, adenomatous polyp was the commonest neoplastic polyp which is comparable to other studies. ${ }^{2,7,9,10}$ Amongst them, 25 (86\%) had tubular and four (14\%) had tubulovillous morphology. High grade dysplasia was noted in three $(10.3 \%)$ of the cases. This finding is similar to many studies which showed predominance of tubular subtype with prevalence varying from $70.3 \%$ to $77 \%$ and high grade dysplasia ranging from $8.6 \%$ to $21.43 \%$. $^{2,9,11}$ Invasive adenocarcinoma in adenomatous polyp was reported ranging from $2.85 \%$ to $5.6 \%{ }^{10,12}$ However, component of invasive adenocarcinoma was not seen in our study. Among the non-neoplastic polyps, hyperplastic polyp (55 cases, $37 \%$ ) was the most common followed by inflammatory (23 cases, $15 \%$ ) and juvenile polyp (10 cases, $7 \%$ ). Similar result pattern was noted by Sharma et al. ${ }^{13}$ This finding, however, is different from many studies which found juvenile polyp to be most prevalent. ${ }^{2,10,11}$ This differing result may be due to the predominance of paediatric population in their studies. $2.5 \%$ of patients in this study were less than 20 years and juvenile polyp constitutes $7 \%$ of the lesions unlike the study of Khajuria et al with 54\% cases less than 20 years. In their study juvenile polyp constituted $48 \%$ of the cases. ${ }^{11}$

The age of the patients ranged from 7 to 84 years with a mean age of 50 years. This finding is in accordance with studies of Chitturi et $\mathrm{al}^{3}$ and Manakkad et al. ${ }^{7}$ The age of the patients ranged from 4 to 88 years with a mean age of 46.59 years in study of Chitturi et al. ${ }^{3}$ Manakkad et al found mean age of 47.14 years with age range of 2-85 years. ${ }^{7}$ A lower mean age was observed in studies with larger volume of paediatric patients. ${ }^{11}$ More than half the cases in our study was noted in 41-60 years age group, comparable to Sharma 
Table 3: Distribution of histological types of polypoidal lesions according to their location in gastrointestinal tract

\begin{tabular}{|c|c|c|c|c|c|c|c|c|c|}
\hline \multicolumn{10}{|c|}{ Site } \\
\hline & Esophagus & GEJ & Stomach & Duodenum & Ileum & Colon & Rectosigmoid & Anal canal & Total \\
\hline Conventional adenoma & 0 & 0 & 3 & 0 & 0 & 12 & 13 & 1 & $29(19 \%)$ \\
\hline Fibroepithelial polyp & 1 & 0 & 0 & 0 & 0 & 0 & 4 & 2 & $7(4.5 \%)$ \\
\hline $\begin{array}{l}\text { Foveolar metaplastic } \\
\text { polyp }\end{array}$ & 0 & 0 & 0 & 10 & 0 & 0 & 0 & 0 & $10(7 \%)$ \\
\hline Fundic gland polyp & 0 & 0 & 6 & 0 & 0 & 0 & 0 & 0 & $6(4 \%)$ \\
\hline Hyperplastic polyp & 0 & 3 & 19 & 4 & 0 & 10 & 19 & 0 & $55(37 \%)$ \\
\hline Inflammatory polyp & 0 & 0 & 0 & 2 & 1 & 8 & 12 & 0 & $23(15 \%)$ \\
\hline Juvenile polyp & 0 & 0 & 0 & 0 & 0 & 4 & 6 & 0 & $10(7 \%)$ \\
\hline Neuroendocrine tumor & 0 & 0 & 0 & 1 & 0 & 0 & 1 & 0 & $2(1.5 \%)$ \\
\hline Parietal cell hyperplasia & 0 & 0 & 1 & 0 & 0 & 0 & 0 & 0 & $1(0.5 \%)$ \\
\hline Peutz Jehgers polyp & 0 & 0 & 3 & 0 & 0 & 0 & 0 & 0 & $3(2 \%)$ \\
\hline Sessile serrated lesion & 0 & 0 & 0 & 0 & 0 & 0 & 1 & 0 & $1(0.5 \%)$ \\
\hline Squamous papilloma & 2 & 0 & 0 & 0 & 0 & 0 & 0 & 0 & $2(1.5 \%)$ \\
\hline $\begin{array}{l}\text { Traditional serrated } \\
\text { adenoma }\end{array}$ & 0 & 0 & 0 & 0 & 0 & 1 & 0 & 0 & $1(0.5 \%)$ \\
\hline Total & $3(2 \%)$ & $3(2 \%)$ & $32(21.5 \%)$ & $17(11 \%)$ & $1(0.5 \%)$ & $35(23.5 \%)$ & $56(37.5 \%)$ & $3(2 \%)$ & $150(100 \%)$ \\
\hline
\end{tabular}

Table 4: Bi- and multivariate analysis of study variables with neoplastic and non-neoplastic polypoidal lesions

\begin{tabular}{|c|c|c|c|c|c|}
\hline \multicolumn{2}{|l|}{ Variables } & No. of pts & Neoplastic & Non-neoplastic & P value \\
\hline \multirow{2}{*}{ Gender } & Male & 87 & 22 & 65 & \multirow{2}{*}{0.319} \\
\hline & Female & 63 & 11 & 52 & \\
\hline \multirow{2}{*}{$\begin{array}{l}\text { Number of polypoidal } \\
\text { lesions }\end{array}$} & Single & 135 & 29 & 106 & \multirow{2}{*}{0.743} \\
\hline & Multiple & 15 & 4 & 11 & \\
\hline \multirow{4}{*}{$\begin{array}{l}\text { Site of Polypoidal } \\
\text { lesions }\end{array}$} & $\begin{array}{l}\text { Esophagus } \\
\text { and GEJ }\end{array}$ & 6 & 0 & 6 & \multirow{4}{*}{.008} \\
\hline & Stomach & 32 & 3 & 29 & \\
\hline & $\begin{array}{c}\text { Small } \\
\text { Intestine }\end{array}$ & 18 & 1 & 17 & \\
\hline & $\begin{array}{l}\text { Large } \\
\text { Intestine }\end{array}$ & 94 & 29 & 65 & \\
\hline
\end{tabular}

Table 5: Correlation of neoplastic nature of polypoidal lesions with continuous variables

\begin{tabular}{lccc}
\hline Variables & Pearson's correlation coefficient (R) & Pvalue \\
\hline Age of patient & -.146 & .075 \\
\hline Size of polypoidal lesions & -.014 & .85
\end{tabular}

et al. ${ }^{13}$ Jayadevan et al found that there was a five-fold increase in the prevalence of colonic polyps over age $40 .{ }^{14}$

Rectosigmoid region was the commonest site (56 cases, $37.5 \%$ ) followed by colon (35 cases, $23.5 \%$ ). This is in agreement with the literature which highlights that colorectal polyps are the most frequently encountered GI polyps..$^{9,10}$ Our study showed low incidence of oesophageal polyps $(n=3,2 \%)$, which coincides with various studies. ${ }^{9,10}$ Site wise, the most common polypoidal lesions were squamous papilloma in oesophagus, hyperplastic polyp in stomach and colorectal region and gastric foveolar metaplastic polyp in duodenum. Hyperplastic polyp and adenomatous polyp was found to be the commonest polyp in stomach and colorectal region resepectively in studies of Gurung et al, Mirzaie et al, Rahat et al and Sharma et al., 2,,12,13 Inflammatory polyp was the commonest duodenal polyp in studies of Gurung et al and Sharma et al. ${ }^{2,13}$ Remaining subtypes of gastric polyps were fundic gland polyp, adenomatous polyp, Peutz Jehgers polyp and polypoidal parietal cell hyperplasia. Adenomatous, inflammatory and juvenile polyps constituted the major bulk of remaining colorectal polyps. One of the inflammatory polyp was associated with ulcerative colitis and remaining were non-specific. There were two cases of neuroendocrine tumor grade 1 , one in duodenum and other in recto-sigmoid location. 134 patients had single polypoidal lesion and multiple lesions were noted in 16 patients. The size of the polypoidal lesion was $<1 \mathrm{~cm}$ in 136 cases, 1-1.9 $\mathrm{cm}$ and $\geq 2 \mathrm{~cm}$ in 7 cases each. Chitturi et al found most of the polyps in their study to be less than $1 \mathrm{~cm}^{3}$ 
Analysis of gender, number, size of polypoidal lesions, and age of the patient with categories of neoplastic versus non-neoplastic pathological nature was not statistically significant. However, a significant association $(p=0.008)$ was found with the site of polypoidal lesions, with notably higher number of neoplastic lesions in the large intestine. Manakkad et al found positive correlation with advancing age of patient and increasing size of lesion in addition to site (with large intestinal predominance of neoplastic lesions, $\mathrm{p}=0.014){ }^{7}$ Atkin et al observed that polyps with size of 1 $\mathrm{cm}$ or larger had significantly higher risk of developing into malignancy. ${ }^{15}$ Mirzaie et al found significant statistical association of neoplastic nature with location of the lesion (most adenomatous polyps in colon) and increasing age of the patient. ${ }^{9}$

\section{CONCLUSIONS}

A spectrum of histological types of polypoidal lesions were found in the GI tract, most commonly in the colorectal region. Hyperplastic polyp and adenomatous polyp were the commonest non-neoplastic and neoplastic polypoidal lesions respectively. A notably higher number of polypoidal lesions in the large intestine were found to be neoplastic in nature compared to other sites.

\section{Conflict of interest: None}

\section{REFERENCES}

1. Turner JR. The gastrointestinal tract, In: Kumar V, Abbas AK, Aster JC. Robbins and Cotran Pathologic basis of disease. 9th edn. Elsevier Saunders; 2015. p.769.

2. Gurung P, Hirachand S, Pradhanang S, Lama S. A histopathological study of gastrointestinal polyps in tertiary care hospital. J Inst Med 2014;36:64-8.

3. Chitturi R, Renuka IV, Latha PP, Vaishnavi R, Manasa BM. Morphologic spectrum of gastrointestinal polyps and polypoid lesions- a five year study. IP Arch Cytol Histopathol Res 2018;3:1515. Crossref
4. O'Connor A, Keane RA, Egan B, Lee N, O'Connor H, Qasim A, Ryan B et al. Adherence to colorectal polyp surveillance guidelines: is there a "scope" to increase the opportunities for screening?. Eur J Cancer Prev 2011;20:40-5. Crossref

5. Aldridge AJ, Simson JN. Histological assessment of colorectal adenomas by size. Are polyps less than $10 \mathrm{~mm}$ in size clinically important?. Eur J Surg 2001;167:777-81. Crossref

6. Cristallini EG, Ascani S, Bolis GB. Association between histologic type of polyp and carcinoma in the stomach. Gastrointest Endosc 1992;38:481-4. Crossref

7. Manakkad SP, Priyadarshini R, Bindu V. Morphological study of intestinal polyps with clinicopathological correlation- 2 years observational study at a tertiary care centre of South India. J Evol Med Dent Sci 2016;5:7491-8. Crossref

8. Lakshmi MRV, Reddy MRP, Shanthi V, Rao NM, Rao BSS, Bhavana G. Clinico histopathological study of gastrointestinal polyps: A prospective study of 160 polypectomy specimens. Indian J Pathol Res Pract 2018;7:64-70. Crossref

9. Zare MA, Abolhasani M, Mobasher MR, Kabivar M. The frequency of gastrointestinal polyps in Iranian population. Iran J Pathol 2012;7:183-9.

10. Patil MV, Rathod U, Deshmukh M, Margam S, Kalgutkar AD. Spectrum of gastrointestinal polyps: A tertiary care hospital experience of five years. Indian J Pathol Oncol 2018;5:656-62. Crossref

11. Khajuria M, Bhardwaj S, Kumari R.A Study into the patterns of gastrointestinal tract polyps. JK Sci 2016;18:81-4. Website

12. Rahat N, Sadiq S. Morphological study of the polypoid lesions of the gastrointestinal tract. Pak J Med Sci 2005;21:318-24.

13. Sharma GL, Kumar LD, Debanth B, Akoijam NJ, Das P, Singh LR. Study of gastrointestinal endoscopic polypectomy specimens in rims hospital. J Evid Based Med Healthc 2018;5:1825-8. Crossref

14. Jayadevan R, Anithadevi TS, Venugopalan SS. Prevalence of colorectal polyps: A retrospective study to determine the cut-off age for screening. J Gastroenterol Pancreatol Liver Disord 2016;3:1-5. Crossref

15. Atkin WS, Morson BC, Cuzick J. Long-term risk of colorectal cancer after excision of rectosigmoid adenomas. $\mathrm{N}$ Engl J Med 1992;326:658-62. Crossref 